\title{
Post-translational modifications of CDK5 and their biological roles in cancer
}

\author{
Gui-Bin Gao ${ }^{1}$, Yue Sun ${ }^{1}$, Run-Dong Fang ${ }^{1}$, Ying Wang ${ }^{2}$, Yang Wang ${ }^{1 *}$ and Qing-Yu He ${ }^{1 *}$
}

\begin{abstract}
Post-translational modifications (PTMs) of Cyclin-dependent kinase 5 (CDK5) have emerged as important regulatory mechanisms that modulate cancer development in patients. Though CDK5 is an atypical member of the cyclindependent kinase family, its aberrant expression links to cell proliferation, DNA damage response, apoptosis, migration and angiogenesis in cancer. Current studies suggested that, new PTMs on CDK5, including S-nitrosylation, sumoylation, and acetylation, serve as molecular switches to control the kinase activity of CDK5 in the cell. However, a majority of these modifications and their biological significance in cancer remain uncharacterized. In this review, we discussed the role of PTMs on CDK5-mediated signaling cascade, and their possible mechanisms of action in malignant tumors, as well as the challenges and future perspectives in this field. On the basis of the newly identified regulatory signaling pathways of CDK5 related to PTMs, researchers have investigated the cancer therapeutic potential of chemical compounds, small-molecule inhibitors, and competitive peptides by targeting CDK5 and its PTMs. Results of these preclinical studies demonstrated that targeting PTMs of CDK5 yields promising antitumor effects and that clinical translation of these therapeutic strategies is warranted.
\end{abstract}

Keywords: CDK5, Posttranslational modifications, Cancer

\section{Introduction}

CDK5 is an atypical member of cyclin-dependent kinases (CDKs) located in chromosome 7q36, which shares large proportion of amino acid sequence identity with other CDK members $[1,2]$. Its activity is required for cell cycle, transcriptional initiation and metabolic cascades $[3,4]$. However, unlike other CDKs, the activation of CDK5 requires specific activators including p35 (CyclinDependent Kinase 5 regulatory subunit 1, CDK5R1) and p39 (Cyclin Dependent Kinase 5 regulatory subunit 2, CDK5R2) that are structurally different from canonical cyclins [5]. CDK5 was firstly discovered in the bovine brain [6] for its function in neuronal development and differentiation [7]. In past decades, the role of CDK5 in cancer development was emerging, which involves in

\footnotetext{
*Correspondence: wangyang8857@gmail.com; tqyhe@email.jnu.edu.cn 'MOE Key Laboratory of Tumor Molecular Biology and Key Laboratory of Functional Protein Research of Guangdong Higher Education Institutes, Institute of Life and Health Engineering, College of Life Science and Technology, Jinan University, Guangzhou 510632, China Full list of author information is available at the end of the article
}

cancer metastasis, proliferation, angiogenesis and chemoresistance. In this review, we introduced the functions of CDK5 in multiple cancer malignant transformation, focusing on various post-translation modifications (PTMs) on CDK5-mediated biological progresses. The advancements of recent investigations on small molecules and competitive inhibitors that specifically target CDK5 or CDK5/p35 complex were also discussed.

\section{The structure and basic function of CDK5}

Similar to other CDK members, CDK5 structurally contains N-lobe, C-lobe, ATP binding domain, activators binding domain, hinge region, PSSALRE helix and Tloop (Fig. 1a). The N-lobe mainly contains $5 \beta$-sheets, while $C$ lobe includes $4 \alpha$-helices. The PSSALRE helix and the DGF motif in T-loop forming a stereo-structure in the surface of CDK5 are critical for activator binding, such as p35 or p25 [5]. The binding of p 25 on CDK5 can effectively tether the conformation and alter the activation loop to an active state (Fig. 1b). In addition, the ATP-binding domain located on the surface of CDK5 


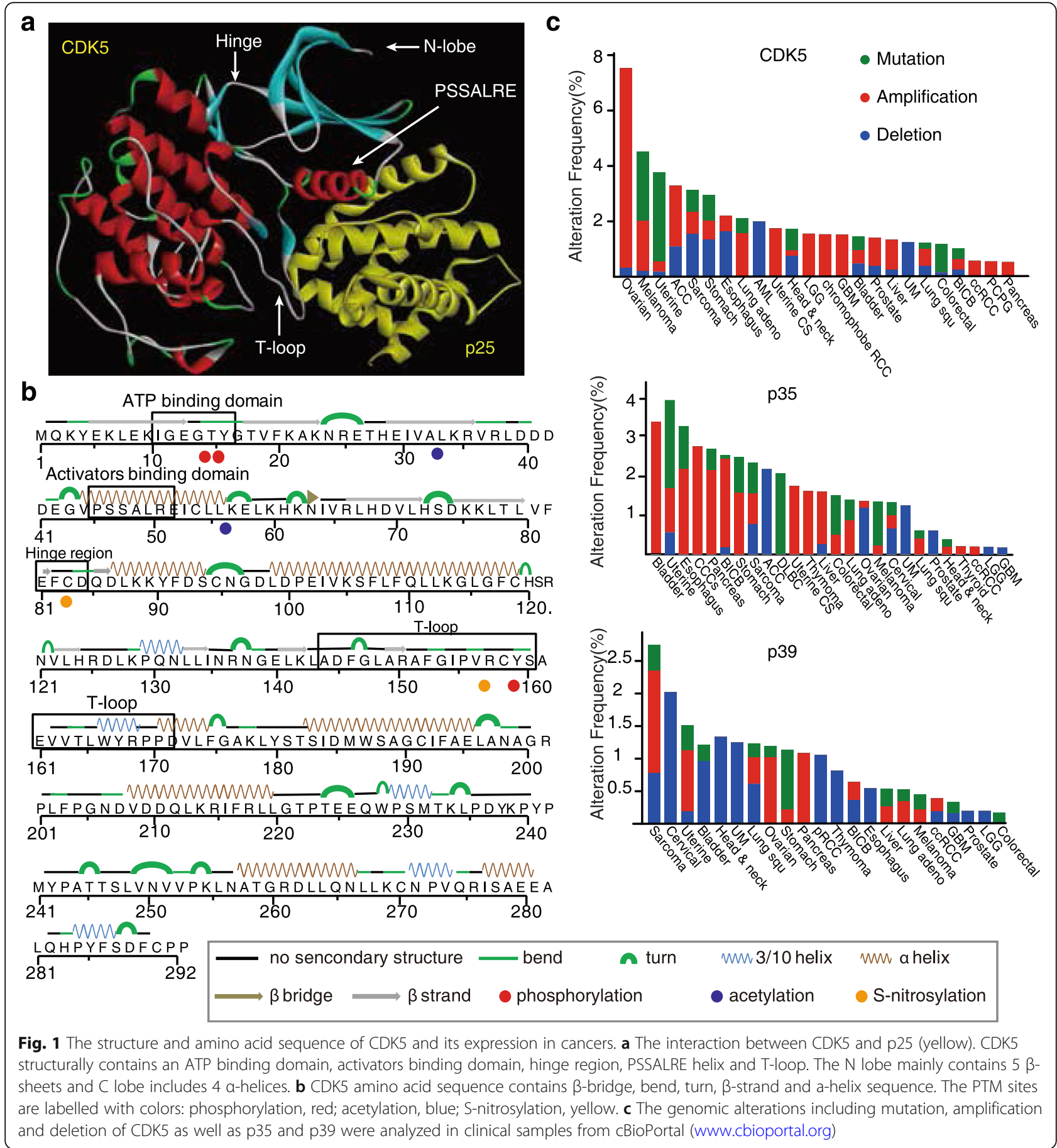

can receive ATP for activation by regulating the crossing of DFG motif to PPD motif; during this progress, hinge region can form hydrogen bonds with the ATP cleft. The functions of these domains can be controlled by various PTMs. For example, in ATPbinding domain, phosphorylation of Thr14 and Tyr15 controlled by the dual specificity kinase Wee1 and Myt1 can influence CDK5 activity [8], whereas phosphorylation of Ser159 in the T-loop of CDK5 contributes to its specific binding to p35 for activation [9]. S-nitrosylation of Cys83, a critical amino acid within the ATP-binding pocket, plays an essential role in regulating the kinase of CDK5 (Fig. 1b). It is clear that PTMs occurred on the different domains play important roles in switching the molecular function of CDK5. 


\section{The activators of CDK5}

CDK5 was recognized to be activated by non-cyclin proteins p35 and p39. p35 is the first regulatory subunit found to bind with CDK5 and control its activity. It is a short half-life protein that can be rapidly degraded through proteasomes [10-13]. When suffered from harmful stimulation, the calpain protease can induce the cleavage of p35 to produce p10 and long half-life p25 in calcium-dependent manner $[14,15]$. Similarly, the cleavage of p39 produces p29 and p10. Importantly, Nterminal p10 region assign of the two proteins underwent myristoylation on Gly2 determines their affinity to cell membrane, which signals for degradation. This can explain that the cleaved forms, p25 and p29 have long half-life than their precursors (Fig. 2). Interestingly, Minegishi et al. swapped cognate p10 regions between p35 and p39, and found that p39 showed a slower degradation rate than p35 [15]. As a unique fragment of p35 or p39, p10 is necessary for the normal function of CDK5 complex in cells. A study showed that p10 protects against CDK5/p25-induced neurotoxicity by inhibiting both PRDX2 (Peroxiredoxin-2) phosphorylation and ROS accumulation in neurons [16]. On the contrary, p10 was reported to induce apoptotic morphologies via a caspases-independent pathway in cortical neurons [17], however, the detailed investigation on p10 in cancer development remains poorly reported.
Increasing studies showed that CDK5 plays an important role in cancer progress. Abnormal expression of CDK5 and its activators are positively associated with multiple tumorigenesis, as summarized in Fig. 1c. A recent study showed that high expression of CDK5 and p35 was observed in late stage of triple-negative breast cancer and correlated with the poor clinical outcome [18]. In glioblastoma, CDK5 expression was observed in $82.8 \%$ of WHO IV glioma [19]. Mechanistically, CDK5 can regulate cell growth, DNA repair and drug resistance in binding with p35 [20]. In contrast, as another activator, p39 expression was found to be decreased in $64 \%$ of human hepatocellular carcinoma, suggesting a tumor suppression role of p39 in HCC [21]. Interestingly, p39 expression is restricted to the postnatal brain [22], and thus its role is less reported in cancer. As shown in Fig. 1c, p39 is genetically deleted in multiple cancer types.

The allele frequencies of mutations on CDK5 are low in various cancer samples, but some mutations located in key domains of CDK5 likely influence its structure and PTMs, which contribute to tumorigenesis. As summarized in Table 1, R156H, A160T, V163G, R168H, P170S/L mutations located in T-loop of CDK5 with allele frequency of $0.1-0.42$ were detected in tumor samples, and mutations R50W/Q, A48T and E50D were found in activators binding domain with allele frequency

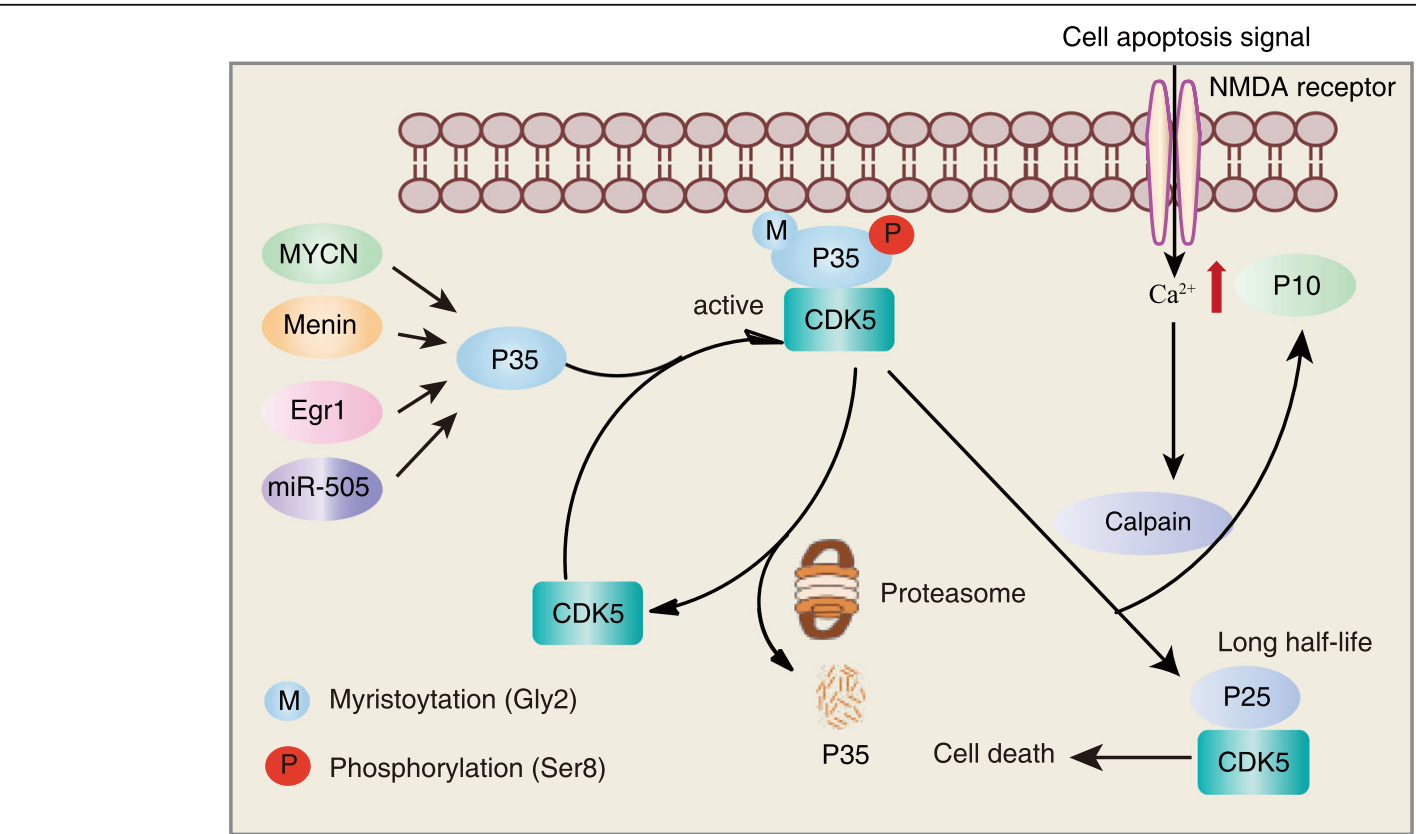

Fig. 2 The mechanism of CDK5 activation. The expression of p35 can be transcriptionally regulated by upstream regulators N-Myc, Menin, EGR1 and miR-505. Myristoylation on Gly2 of p35 determines its affinity to cell membrane, which signals for proteasomal degradation. Activated CDK5 phosphorylates p35 on Ser8 to sustain its cytoplasmic localization. When the cell faces with the death signal, the N-methyl-D-aspartate (NMDA) receptor on the cell membrane can be activated, enhancing the uptake of calcium for calpain activation. Calpain has proteolytic activity to cleave p35 into p25 fragment, a more stable protein than p35. This cleavage leads to the translocation of CDK5/p25 complex into the nucleus and prolongs the activation time of CDK5, which induces the pathological signal pathway of cell death 
Table 1 Summary of mutation sites in corresponding domain of CDK5 and their allele frequencies in clinical cancer samples

\begin{tabular}{|c|c|c|c|c|}
\hline Cancer & Mutation & Mutation Type & Allele Frequency & Relative domain \\
\hline \multirow[t]{11}{*}{ Melanoma } & P240L & Missense & 0.21 & Empty \\
\hline & $\mathrm{R} 156 \mathrm{H}$ & Missense & 0.29 & T-loop \\
\hline & A196G & Missense & 0.21 & Empty \\
\hline & P204L & Missense & 0.58 & Empty \\
\hline & P204S & Missense & 0.09 & Empty \\
\hline & G138V & Missense & 0.12 & Empty \\
\hline & P100S & Missense & 0.09 & Empty \\
\hline & X161splice & Splice & 0.1 & T-loop \\
\hline & $\mathrm{P} 100 \mathrm{H}$ & Missense & 0.2 & Empty \\
\hline & X217splice & Splice & 0.08 & Empty \\
\hline & L173F & Missense & 0.2 & Empty \\
\hline \multirow[t]{17}{*}{ Uterine } & D73N & Missense & 0.46 & Empty \\
\hline & R50W & Missense & 0.29 & $A B D$ \\
\hline & $\mathrm{R} 168 \mathrm{H}$ & Missense & 0.28 & T-loop \\
\hline & D99N & Missense & 0.34 & Empty \\
\hline & $\mathrm{R} 274 \mathrm{H}$ & Missense & 0.09 & Empty \\
\hline & Q282H & Missense & 0.19 & Empty \\
\hline & N62S & Missense & 0.56 & Empty \\
\hline & R217Q & Missense & 0.4 & Empty \\
\hline & A244T & Missense & 0.09 & Empty \\
\hline & G113W & Missense & 0.39 & Empty \\
\hline & N270D & Missense & 0.04 & Empty \\
\hline & D92V & Missense & 0.29 & Empty \\
\hline & D40Y & Missense & 0.07 & Empty \\
\hline & F286L & Missense & 0.33 & Empty \\
\hline & X265_splice & Splice & 0.1 & Empty \\
\hline & F19L & Missense & 0.13 & Empty \\
\hline & K237N & Missense & 0.28 & Empty \\
\hline \multirow[t]{2}{*}{ Sarcoma } & A160T & Missense & 0.16 & T-loop \\
\hline & D184N & Missense & 0.12 & Empty \\
\hline \multirow[t]{4}{*}{ Stomach } & $\mathrm{T} 221 \mathrm{M}$ & Missense & 0.26 & Empty \\
\hline & P170S & Missense & 0.27 & T-loop \\
\hline & R125M & Missense & 0.13 & Empty \\
\hline & V64L & Missense & 0.2 & Empty \\
\hline \multirow[t]{3}{*}{ Lung adeno } & I183F & Missense & 0.23 & Empty \\
\hline & V249E & Missense & 0.16 & Empty \\
\hline & G43S & Missense & 0.25 & Empty \\
\hline \multirow[t]{4}{*}{ Head \& neck } & $\mathrm{A} 48 \mathrm{~T}$ & Missense & 0.24 & $A B D$ \\
\hline & P170L & Missense & 0.3 & T-loop \\
\hline & G138V & Missense & 0.14 & Empty \\
\hline & P228L & Missense & 0.36 & Empty \\
\hline \multirow[t]{2}{*}{ Bladder } & A31T & Missense & 0.26 & Empty \\
\hline & L32V & Missense & 0.07 & Empty \\
\hline Lung squ & A48T & Missense & 0.38 & ABD \\
\hline
\end{tabular}


Table 1 Summary of mutation sites in corresponding domain of CDK5 and their allele frequencies in clinical cancer samples (Continued)

\begin{tabular}{lllll}
\hline Cancer & Mutation & Mutation Type & Allele Frequency & Relative domain \\
\hline Colorectal & R200W & Missense & 0.11 & Empty \\
& R200Q & Missense & 0.34 & Empty \\
& V163G & Missense & 0.13 & T-loop \\
& R50Q & Missense & 0.35 & ABD \\
& F91V & Missense & 0.26 & Empty \\
G11W & Missense & 0.7 & ATP-BD \\
V162L & Missense & 0.42 & T-loop \\
E101Q & Missense & 0.73 & Empty \\
& K61N & Missense & 0.55 & Empty \\
E51D & Missense & 0.46 & ABD \\
D99N & Missense & 0.09 & Empty \\
K33Nfs*3 & FS del & 0.08 & acetylation \\
\hline
\end{tabular}

of 0.38-0.46, and G11W (allele frequency: 0.7) was mutated in ATP binding domain. Whether these mutations on CDK5 influence its PTMs requires more clinical and biological evidences.

\section{The biological function of CDK5 in cancer progression}

Hyperactivation and overexpression of CDK5, as well as its activators p35 and p39, are frequently observed in colon cancer [23], breast cancer [24], lung cancer [25], thyroid cancer [26], pituitary adenoma [27] and prostate cancer [28], which regulate series events of cancer progression including proliferation, DNA damage response (DDR), apoptosis, migration, angiogenesis and immune evasion. During cancer development, p35 and p39 are upregulated in response to DNA damage. N-Myc (MYCN) transcriptionally binds to the promoter of p35 and p39 to promote their expressions [29]. Menin (MEN1) was reported as direct transcriptional factor of p35 to facilitate its expression, and therefore modulating synaptic plasticity [30]. During the differentiation of human leukemia to monocytes, EGR1 can increase the expression of p35 to activate CDK5 for cell differentiation [31]. In post-transcriptional level, microRNA-505$5 p$ functions as a tumor suppressor by targeting CDK5 in cervical cancer [32] (Fig. 2). These examples partially explain the co-occurrence of CDK5 and p35 frequently observed in cancer, more upstream regulators should be further investigated.

\section{The cellular distribution of CDK5}

The cellular localization of CDK5 is closely related to its biological functions, and determined by its PTMs or the activity of p35 and p39. By forming complexes with p35 or p39, CDK5 can attach on cellular membrane or shuttle between cytoplasm and nucleus to exert its molecular functions. N-terminal p10 region of p39 and p35 containing localization motifs undergoes myristoylation that determines its membrane association, while removal of myristoylation on p39 or p35 can induce the nuclear localization of CDK5 [33]. Interestingly, CDK5 activity was reported to influence the cytoplasmic localization of p35-CDK5 and p39-CDK5 through phosphorylation of p35 or p39 on Ser8 (Fig. 2). Inhibition of CDK5 kinase activity causes dephosphorylation and perinuclear accumulation of p35 or p39 [34]. It is estimated that approximately $25 \%$ of CDK5-p35 complexes are associated with membranes via ionic interactions together with lipidic interactions [35]. CDK5 can phosphorylate amphiphysin 1 on Ser276 and Ser285 to enhance its presence on lipid membrane for the regulation of synaptic vesicle endocytosis [36]. Another study showed that CDK5 localizes in the mitochondria-associated endoplasmic reticulum membrane (MAM), and regulates mitochondrial $\mathrm{Ca}^{2+}$ homeostasis. Deletion of CDK5 triggers mitochondrial permeability transition pore (mPTP) opening and mitochondrial $\mathrm{Ca}^{2+}$ transfer from the endoplasmic reticulum (ER) to the mitochondria [37]. More PTM events controlling the cellular localization of CDK5 remain further studied.

\section{PTM events in CDK5-mediated cancer proliferation}

Cell cycle disorder and abnormal proliferation are two hallmarks of cancer cells. Major cell cycle regulators, such as CDKs, have been widely studied for their role in promoting cancer cell proliferation [38]. In addition, Noxa is constitutively expressed in cancer cells, and the CDK5 overexpression can promote the Noxa transfer from cytoplasm to mitochondria, participating in glucose metabolism to provide energy for nucleotide synthesis 
[39]. Huang et al. found that CDK5 is highly expressed in prostate, lung and breast cancer, which located in the nucleus and participates in the nuclear $\mathrm{p} 21^{\mathrm{CIP} 1}$ protein degradation [40]. In non-small cell lung cancer (NSCL $\mathrm{C})$, the positive staining of CDK5 and $\mathrm{p} 35$ was observed in the cytoplasm of malignant cells [41].

As a proline-directed kinase, CDK5-mediated phosphorylation signaling cascade exhibits chief effect on multiple cancer progression (Fig. 3, Table 2). In glioblastoma (GBM), CDK5 can amplify EGFR signaling by phosphorylating CRMP2 (collapsin response mediator protein 2) at Ser522, sustaining the pro-proliferation effect on tumor cells [46]. Retinoblastoma protein ( $\mathrm{Rb})$, a key cell cycle regulator that binds to E2F for preventing cell proliferation, was reported to be a downstream substrate of CDK5 [47]. In medullary thyroid, CDK5 activation can enhance the expression of E2F downstream target genes CDK2, $\mathrm{p} 15^{\mathrm{INK} 4 \mathrm{~b}}$ and $\mathrm{p} 21^{\mathrm{CIP} / \mathrm{WAF} 1}$ to promote cell proliferation (Fig. 3a). It phosphorylates $\mathrm{Rb}$ at Ser807/Ser811 to release transcription factor E2F for initiating cell cycle [26]. In addition, CDK5-mediated cMyc phosphorylation at Ser62 can abolish Bridging integrator 1 (BIN1)/c-Myc interaction, ultimately facilitating the progression of NSCLC [48]. Recent study showed that CDK5 activated by EGFR can phosphorylate TRIM59 (Tripartite motif-containing 59) at Ser308, which recruits PIN1 (Peptidylprolyl Cis/Trans Isomerase, NIMA-Interacting 1) for TRIM59 cis-trans isomerization. The isomerized TRIM59 undergoes a nucleus translocation via binding to importin $\alpha 5$, and enhances STAT3 signaling for promoting tumorigenesis by inducing ubiquitination and degradation of tumor suppressor histone variant macroH2A1 [49].

\section{PTM events in CDK5-mediated DNA damage response and DNA repair}

During tumor progression, a decrease of damaged surveillance mechanism and an enhancement of genome instability are necessary for cancer cells to achieve uncontrolled growth and the adaptability associated with aggressive tumors [50]. Deregulation of DNA damage response (DDR) plays an important role in cancer development [50-52]. CDK5 was reported to participate in the DDR process mainly by phosphorylating series major DDR proteins (Fig. 3a), such as ATM (ataxia-telangiectasia mutant) and Ape1 (apurinic/apyrimidine endonuclease 1) [53, 54]. The inhibition of CDK5 kinase activity was linked to suppression of DDR process and tumor progression. Courapied and the colleagues found that CDK5 can influence the DDR process by up-regulating the basic meiotic structure-specific Eme1 (Essential Meiotic Structure-Specific endonuclease 1) mediated by STAT3 [55]. DNA damage stimulation leads to the upregulation of CDK5, which induces the phosphorylation of Ser727 on STAT3 to activate STAT3, indicating that CDK5-STAT3-Eme1 signaling plays a critical role in DNA damage repair (Fig. 3a).

Many traditional chemotherapeutic agents are DNA damage stimulators, for instant, ionizing radiation and topoisomerase inhibitors can enhance the activity of CDK5 in cancer cells. CDK5 is able to induce the phosphorylation of ATM at Ser729, to activate DNA damage repair to promote cancer proliferation [56]. In addition, knockdown of CDK5 can decrease the cellular DNA damage repair ability and inhibit tumor cell growth [57], suggesting that inhibition of CDK5 in combination with traditional chemotherapeutic agents may be an effective strategy for cancer treatment.

\section{Dual role of CDK5 PTMs in apoptosis}

The dual role of CDK5 in apoptosis was found in different diseases, depending on the occurrence of PTMs at specific proteins/sites. Hsu et al. found that CDK5/p35 complex can induce the Ser81 phosphorylation of AR (androgen receptor) to inhibit cell apoptosis and promote cell proliferation in prostate cancer [58]. Recent study showed that CDK5-mediated Mcl-1 phosphorylation can lead to the inactivation of the apoptosis signal pathway in PDAC (Pancreatic ductal adenocarcinoma) [59]. The above observations demonstrated that CDK5mediated PTM events play a critical role in controlling apoptosis.

\section{PTMs on CDK5 for cancer metastasis}

Metastasis is a key feature in cancer progression, and the activity of CDK5 was found to be associated with invasive phenotype, such as cytoskeleton remodeling [60]. A study showed that the mutant form of K-Ras ${ }^{\text {G12D }}$ promotes the generation of p25 that further enhances the activity of CDK5 in pancreatic cancer, resulting in the activation of Ral (Ras-Like) pathway and morphological change conducive to cell migration [42, 60,61]. In breast cancer, EGF (epidermal growth factor) stimulation activates CDK5 to phosphorylate Girdin ( $\mathrm{G} \alpha$-interacting vesicle associated protein) at Ser1674, which activates the downstream G-coupled receptor-dependent signaling pathway for promoting cell migration [62] (Fig. 3b). Increasing evidences proved that $\mathrm{CDK} 5$ is involved in the regulation of the microtubule complex that is necessary for cell movement. For example, the Ser202 phosphorylation of microtubule-associated protein Tau [63], the Ser522 phosphorylation of CRMP-2 (Collapsin Response Mediator Protein-2) [64] and the Ser16 phosphorylation of STMN1 (stathmin, microtubule decomposing protein) [65] are all CDK5 substrates that associated with carcinogenesis and tumor migration. Furthermore, CDK5 can promote tumor migration through the Ser425 phosphorylation of talin and the 


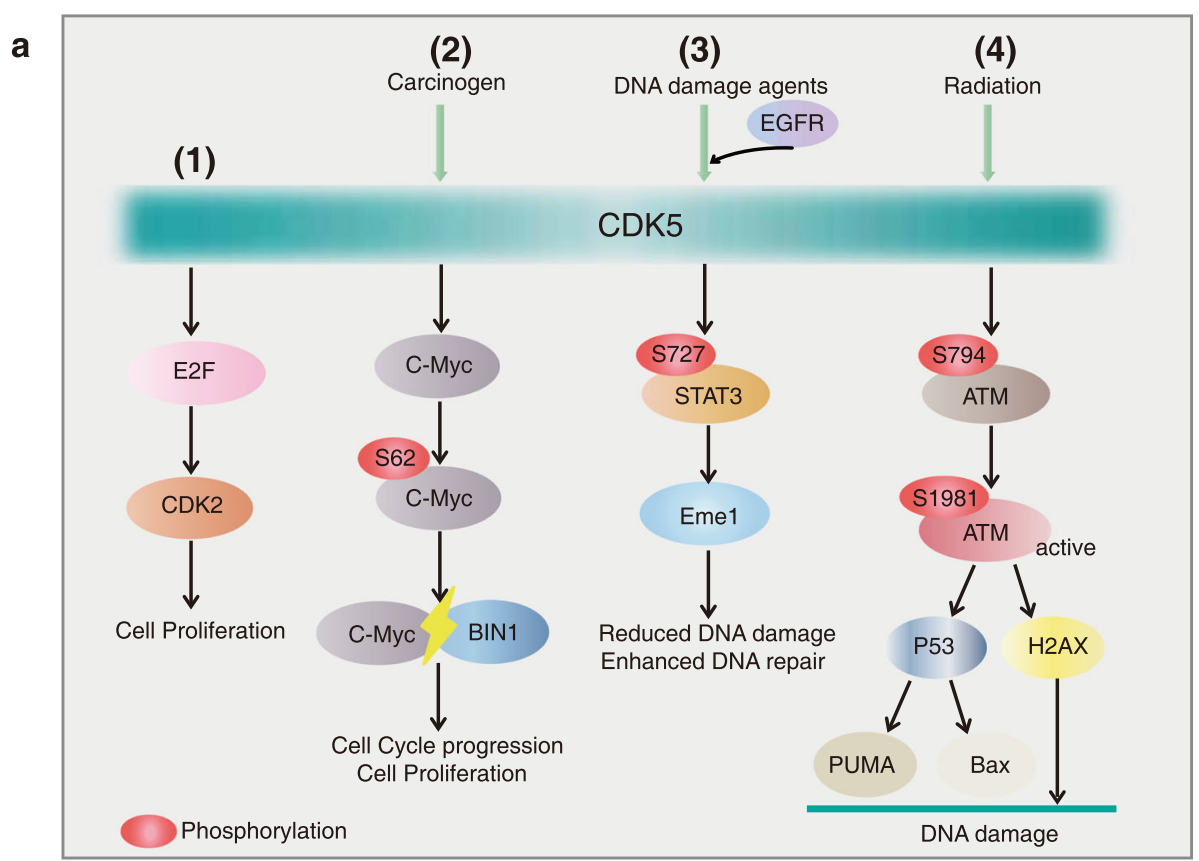

b

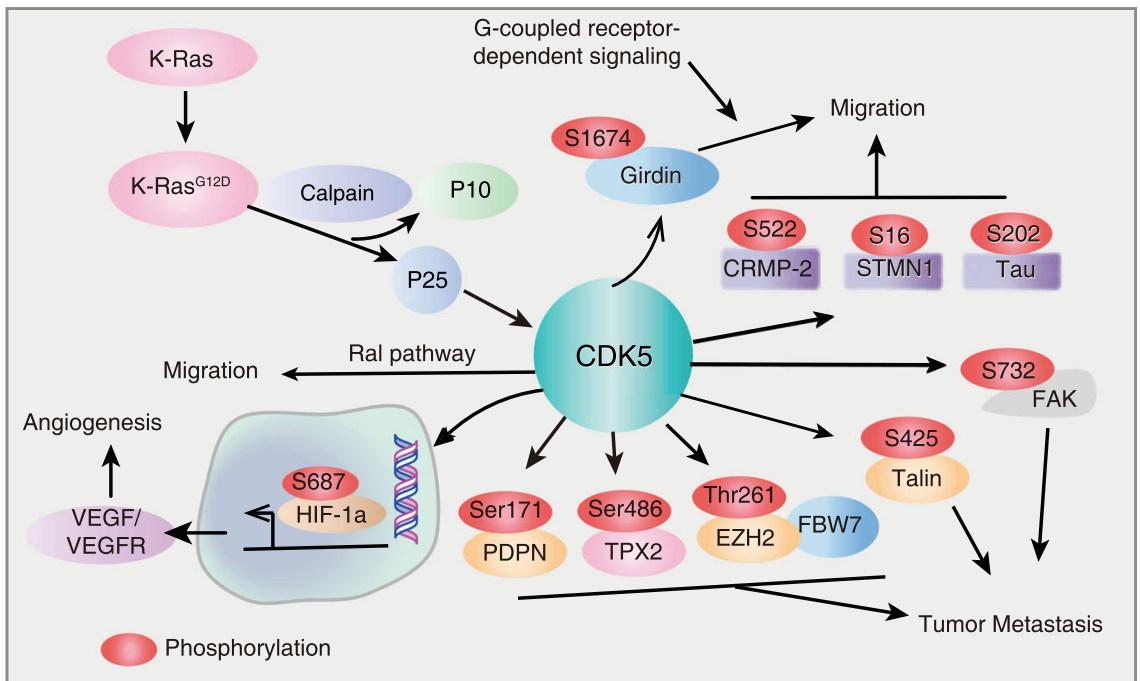

Fig. 3 PTM events in CDK5-mediated biological function in cancer progression. a PTM events in CDK5-mediated cell proliferation and DNA damage repair. (1) In cancer cells, CDK5 mediates cell proliferation through activating E2F-CDK2 pathway. (2) CDK5 induces C-Myc Ser62 phosphorylation for abolishing Bridging integrator 1 (BIN1)/C-Myc interaction, promoting cell cycle progression. (3) During DNA damage, CDK5 can be up-regulated or phosphorylated by EGFR, inducing the phosphorylation of Ser727 on STAT3, the activated STAT3 promotes the expression of Eme1 gene to initiate DNA damage repair. (4) In response to radiation, ATM can be phosphorylated by CDK5 at Ser794 and undergoes autophosphorylation at Ser1981 for activation, which signals for p53 and H2AX pathways to initiate DNA damage repair. $\mathbf{b}$ The mechanism of CDK5 in apoptosis, cell migration and angiogenesis. CDK5 is activated upon EGF stimulation, which regulates downstream proteins phosphorylation, including Girdin, STMN1, CRMP-2, Talin and FAK to promote cell movement and migration. K-Ras ${ }^{\mathrm{G} 12 \mathrm{D}}$ promotes the production of p25 to enhance the activity of CDK5, which results in the activation of Ral (Ras-Like) pathway and morphological changes conducive to cell migration. In addition, CDK5 regulates angiogenesis through directly controlling the HIF1a target gene, VEGF and its receptor expression

Ser732 phosphorylation of FAK (Focal adhesion kinase) [66] (Fig. 3b). Jin et al. found that CDK5 regulates Thr261 phosphorylation in EZH2 (Enhancer of zeste homolog 2), a component of the polycomb repressive complex 2 (PRC2). The phosphorylated EZH2 can bind to FBW7 (F-box and WD repeat domain-containing 7) for degradation to prevant pancreatic cell migration and invasion [67]. In addition, CDK5 can inhibit mouse cell migration through Ser171 phosphorylation in PDPN (Podoplanin) [68]. Recent studies found that CDK5- 
Table 2 CDK5 mediated phosphorylation events in cancers

\begin{tabular}{lllll}
\hline Cancers & Protein & Positions & Signal pathways & References \\
\hline Pancreatic & K-Ras & Gly12 mutant Asp12 & MEK, PI3K, CDK5 signaling and regulatory pathways & [42] \\
Medullary thyroid carcinoma & STAT3 & Ser727 phosphorylation & STAT3 pathway & [43] \\
Non-small cell lung & C-Myc & Ser62 phosphorylation & C-Myc pathway & [44] \\
Small cell lung & C-Myc & Ser62 phosphorylation & C-Myc pathway & {$[44]$} \\
Colorectal & ERK5 & Thr732 phosphorylation & ERK5-AP-1 pathway & {$[23]$} \\
Breast & FAK & Ser732 phosphorylation & CDK5-FAK pathway & {$[24]$} \\
Glioblastoma multiforme & PIKE-A & Ser279 phosphorylation & PIKE-A-Akt pathway & {$[45]$} \\
\hline
\end{tabular}

mediated phosphorylation of TPX2 (Target protein for Xklp2) at Ser486 stabilizes TPX2 to promote the migration of hepatocellular carcinoma cells [69] (Fig. 3b). Collectively, CDK5-mediated phosphorylation cascade is critical for tumor metastasis, suggesting that targeting CDK5 is a promising strategy for preventing cancer spread.

\section{PTM events in CDK5-mediated tumor angiogenesis}

Angiogenesis is the physiological process of growing new blood vessels from existing blood vessels, which provides nutrition and oxygen for tumor growth. Julia Herzog et al. showed that CDK5 is the main regulator of angiogenesis in hepatocellular carcinoma (HCC). CDK5 can directly phosphorylate HIF1 $\alpha$ (hypoxia inducible factor $1 \alpha)$ at Ser687 to enhance the expression of its target genes VEGFA, VEGFR1 and EphrinA1, which are essential for the formation of novel blood vessels in tumors [70] (Fig. 3b). In U87 glioblastoma and Lewis lung cancer, inhibition of CDK5 can reduce VEGF expression to inhibit angiogenesis [71]. Taken together, CDK5 is also a potential target for inhibiting angiogenesis in cancer therapy.

\section{PTM events in CDK5-mediated immune evasion}

Immune evasion often occurs through the mechanism of peripheral tissue tolerance in cancers, for example, inhibiting the expression of programmed cell death ligand 1 (PD-L1) can produce potent anti-tumor immunity [72]. Recent study showed that CDK5 has the function of regulating $\mathrm{PD}-1 / \mathrm{PD}-\mathrm{L} 1$ pathway in immunity. Dorand et al. found that CDK5 can directly or indirectly inhibit the activity of phosphorylase to inhibit regulatory factor 2 binding protein 2 (IRF2BP2) at Ser360 phosphorylation, which further leads to tumorigenesis [73]. Simultaneously, they found that inhibition of CDK5 activity can regulate the continuous expression of interferon regulatory factor 2 (IRF2) and interferon IRF2BP2 in medulloblastoma (MB) mouse model, decreasing PD-L1 expression and then eliminating immune evasion [72]. In addition, aPBAE/Cas9-CDK5 nanoparticles developed by Huan Deng et al. can effectively knock out CDK5 in vitro, resulting in down-regulation of PD-L1 expression and inhibition of tumor growth [74].

\section{Various types of PTMs on CDK5}

With the advanced mass spectrometric technology developed, new PTMs on CDK5 including glycosylation, phosphorylation, ubiquitin, sumoylation and acetylation were identified to play important roles in tumorigenesis [75-77]. These PTMs are found to be essential for modulating the activity of CDK5 during tumor occurrence and development. The new discovery of PTM sites on CDK5 is shown in Table 3 and their biological functions are outlined as follows.

\section{Phosphorylation events relevant to CDK5}

CDK5 phosphorylation and CDK5-mediated phosphorylation events were reported to play critical roles in degenerative neurological diseases and cancer [13]. Phosphorylation on CDK5 is the most widely investigated PTM that contributes to the activity of CDK5. Zukerberg et al found that c-Abl can induce Tyr15 phosphorylation of CDK5 to promote neurite outgrowth [78]. Ehrlich and colleagues found that Tyr15 phosphorylation of CDK5 and p35 is upregulated in human hepatoblastoma cell lines as compared to primary human hepatocytes [56]. In GBM tumorigenicity, Tyr15 phosphorylation of CDK5 activated by EGFR phosphorylates TRIM59 at Ser308 to promote tumor growth [49]. The activity of CDK5 is inhibited by phosphorylation of Thr14, since the phosphorylation causes the misalignment of the ATP-phosphate group and the change of the $\mathrm{Mg}^{2+}$ ion coordination sphere, as well as the G-loop to shift away from the ATP binding site [8]. Phosphorylation of Ser159 on CDK5 was also reported to display an inhibitory role in the activity of CDK5 kinase [9].

For CDK5-mediated phosphorylation events, its substrates are involved in a variety of biological processes regulation and are closely related to the occurrence and development of cancer. For example, the activity of CDK5 during neuronal development can be realized by phosphorylation of p35 at Thr138 position $[79,80]$. Recent study found that, as a downstream target of CDK5, 
Table 3 PTMs on CDK5 and their relevant functions

\begin{tabular}{lll}
\hline Positions & PTM types & Molecular Functions \\
\hline Thr14 & Phosphorylation & Decreases CDK5 activity \\
Tyr15 & Phosphorylation & Increases CDK5 activity and promotes cell growth \\
Lys33 & Acetylation & Decreases CDK5 activity by inducing CDK5 loss ATP binding ability \\
Lys56 & Acetylation & Unknown \\
Cys83 & S-nitrosylation & Increases CDK5 activity; Regulates the development of neurons \\
Cys157 & S-nitrosylation & Increases CDK5 activity; Regulates the development of neurons \\
Ser159 & Phosphorylation & Decreases CDK5 activity kinase \\
\hline
\end{tabular}

$\mathrm{Rb}$ is phosphorylated by CDK5, eventually increasing the expression of cyclin and other CDKs [26]. On the other hand, inhibiting CDK5 activity can decrease calmodulin Tyr27 phosphorylation, thereby reducing melanoma cell cytoskeleton remodeling, metastasis and invasion [61]. Furthermore, CDK5 enhances PI3K/AKT signal transduction by phosphorylation of $\mathrm{G} \alpha$-interacting vesicle associated protein at Ser1674 position, which leads to cell migration [62].

\section{S-nitrosylation of CDK5}

S-nitrosylation refers to the addition of NO group to a cysteine residue of certain proteins, which plays diverse regulatory roles in multiple physiological processes. Its

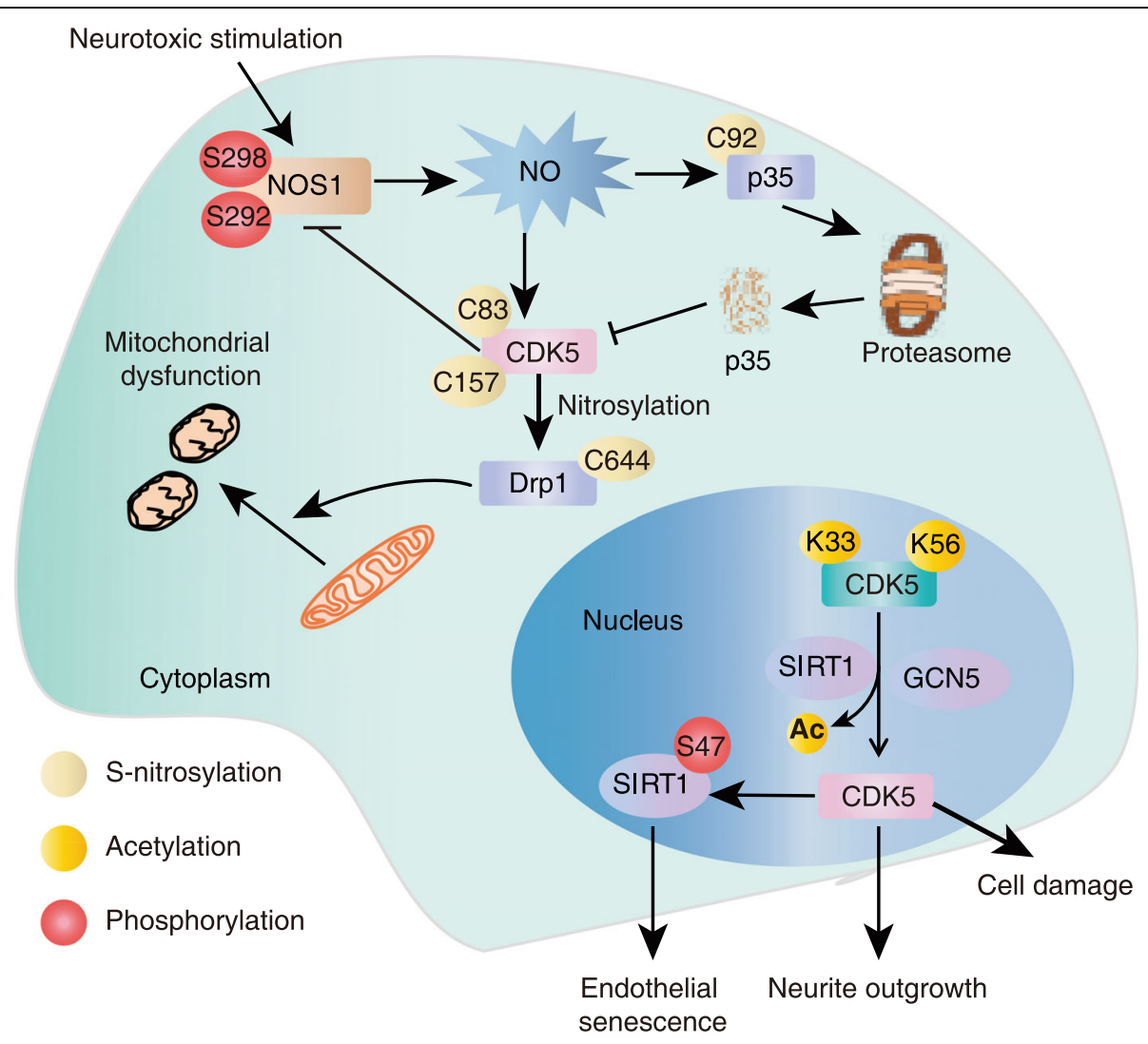

Fig. 4 S-nitrosylation and acetylation of CDK5 in cell. The interaction between NOS1 and CDK5 promotes the formation of SNO-CDK5, and then SNO-CDK5 may transfer NO group to DRP1 by transnitrosation, resulting in excessive mitochondrial division and subsequently mitochondrial dysfunction. SNO-CDK5 phosphorylates NOS1 on S292 and S298, creating a negative-feedback loop by suppressing NOS1 activity. In addition, NO is able to negatively regulate the activity of CDK5 by inducing p35 S-nitrosation at C92 for controlling the development of neuronal cells. In nucleus, the acetylation of CDK5 at K33 and K56 mediated by SIRT1 and GCN5 leads to the loss of ATP binding and the impairment of kinase activity, which regulates multiple cellular processes, including neurite outgrowth and cell damage. The activated CDK5 can in turn phosphorylate SIRT1 at S47 that contributes to cell senescence 
role in cancer development was widely investigated in recent years. In breast cancer, S-nitrosylation of Ras induces MAPK-dependent phosphorylation and activates ETS-1 (Erythroblastosis virus transcription factor-1), a critical mediator of nitric oxide, resulting in an aggressive breast cancer phenotype [81]. S-nitrosylation of $\mathrm{H}$ Ras also restricts Raf-1 activation and further signals propagation via ERK-1/2 [82].

In CDK5, Cys83 and Cys157 can be S-nitrosylated, which leads to overactivation of CDK5 and subsequently contributes to mitochondrial dysfunction, synaptic damage and neuronal cell death. A study showed that the interaction between neuronal NOS1 (nitric oxide synthase) and CDK5 contributes to the formation of SNO-CDK5 [83]. Subsequently, SNO-CDK5 transfers the NO group to Drp1 (dynamin-related protein 1) through trans-nitrosation, the formation of S-nitrosoDrp1 leads to excessive mitochondrial division and synaptic failure [84]. In turn, hyperactivated CDK5 phosphorylates NOS1 and suppresses its activity in a negative regulatory-feedback loop [85] (Fig. 4). On the contrary, zhang et al. proved that the mutation of Cys83 Snitrosylation on CDK5 restores its kinase activity and enhances dendritic growth and branching [86]. NO acts as a molecular switch to negatively regulate the activity of CDK5 in a p35 S-nitrosation-dependent way for controlling the development of neuronal cells [87]. Considering the fact that CDK5 phosphorylates many target substrate proteins, it is possible that CDK5 may also nitrify these substrates to influence multiple biological progresses [7]. In addition, the imbalance of CDK5 activity may play a role not only in AD (Alzheimer's disease), but also in several neurodegenerative diseases. However, the S-nitrosylation of CDK5 involved in tumorigenesis remains to be studied, thus it is interesting to investigate the role of SNO-CDK5 in cancer development.

\section{Sumoylation and acetylation on CDK5}

Sumoylation is involved in cell biological processes such as cell cycle regulation, senescence, and apoptosis [88, 89]. Recent experiments showed that the deregulation of the sumo pathway promotes carcinogenic transformation by affecting (de) sumoylation of many oncoproteins and tumor suppressors [90]. Sumoylation on the complex of CDK5/p35 is associated with the activity of CDK5 kinase [91]. Anja Büchner et al. used coimmunoprecipitation assay to investigate the effect of sumoylation on CDK5/p35 complex formation. They found that p35 is a novel sumoylation target, in which p35 sumoylation can enhance the formation of CDK5/ p35 complex [92], however, it is not clear whether sumoylation can directly act on CDK5. The details for how the sumoylation of CDK5 is involved in regulating the occurrence and development of tumor remain to be studied.

K33 and K56 are two acetylation sites of CDK5 that were firstly identified by Juhyung Lee et al. in 2014 [93]. They found that the acetylation of K33 on CDK5 in the nucleus can lead to the loss of ATP binding ability and the destruction of kinase activity [94]. In addition, their experiments further demonstrated that GCN5 (General control of amino acid synthesis protein 5) and SIRT1 (Sirtuin-1) are the key factors for deacetylation of CDK5. Thus, SIRT1 inhibitors can enhance acetylation of CDK5 for decreasing its activity (Fig. 4). However, the biological function of $\mathrm{K} 56$ of CDK5 remains to be studied [95, 96]. Interestingly, hyperactivation of CDK5 is able to phosphorylate SIRT1 at S47 to influence cellular senescence [97]. Regarding the functional role of the acetylation modification of CDK5 in neurological diseases, and whether CDK5 also plays a similar role in the development of cancer require further investigations.

\section{Targeting CDK5 and its PTMs as potential cancer therapies}

Clinical trials of CDK inhibitors in cancer therapy

Hyperactivation of CDKs was frequently recorded in most primary tumors, and thus were deemed as useful targets for clinical cancer therapy. Since CDK activity relies on ATP, most of the current CDKs inhibitors are based on targeting ATP binding pocket. For example, flavopiridol, the first pan-CDK inhibitor used in human clinical trials, can bury in the ATP-binding pocket of CDKs, and inhibits their activity at nanomolar dosage [98]. Several phase I clinical trials showed that flavopiridol has an antitumor effect in patients with renal, prostate and colon cancer [99]. In the past decade, many classes of CDK inhibitors were under investigation in clinical trials, such as olomoucine, roscovitine, kenpaullone and SNS-032, which achieved significant therapeutic significance in clinic. Another successful example is CDK4/6 inhibitors, three CDK4/6 inhibitors including palbociclib, ribociclib and abemaciclib have currently received FDA approval for clinical use [100]. Mechanically, these inhibitors can inhibit $\mathrm{Rb}$ protein phosphorylation and arrest the cell cycle in G1 phase to inhibit proliferation [100]. Though the PTMs on CDKs are essential for their functions, the inhibitors that specifically modify PTMs of CDKs are lacking in clinical trials.

\section{The inhibitors of CDK5 in cancer}

Considering the oncogenic role of CDK5 in cancer, targeting the ATP binding of CDK5 and CDK5-p35 interaction is currently the two major strategies to suppress CDK5 activity, which has been used in preclinical trials of drugs for several types of tumors (Table 4) [114-116]. Under phase II clinical trials, dinaciclib (SCH 727965) is 
Table 4 Summary of CDK5 inhibitors

\begin{tabular}{|c|c|c|c|c|}
\hline Inhibitors & Type & Major Targets & Disease(s) & References \\
\hline PHA-767491 & Drug like & CDK1, CDK2, CDK5, CDK9 & Cervical; Breast & {$[101,102]$} \\
\hline PHA-793887 & Drug like & CDK1, CDK2, CDK4, CDK5, CDK7, CDK9 & Myeloma; Lung & {$[103,104]$} \\
\hline Flavopiridol & ATP-competitive & CDK1, CDK2, CDK5, CDK9 & Retinoblastoma protein & [105] \\
\hline Dinaciclib (SCH727965) & ATP-competitive & CDK1, CDK2, CDK5, CDK9 & Prostate & [105] \\
\hline Roscovitine (Seliciclib, CYC202) & ATP-competitive & CDK2, CDK5 & Liver; Lymphoma & [106] \\
\hline Hymenialdisine & ATP-competitive & CDK5, GSK3ß, CDK2, CDK1, Chk1 & Alzheimer's disease & [107] \\
\hline Purvalanol-A & ATP-competitive & CDK1, CDK2, CDK5 & Breast & [108] \\
\hline Indirubin-5 & ATP-competitive & CDK1, CDK2, CDK5 & Leukemia & [109] \\
\hline AT7519 & ATP-competitive & CDK2, CDK4, CDK5, CDK9 & Colon; Leukemia & [110] \\
\hline CIP (peptide derived from p53) & Peptide competing with Substrate & CDK5/p25 & Pancreatic & [111] \\
\hline CIP (peptides derived from p35) & Peptide competing with Substrate & CDK5/p35 & Alzheimer's disease & [112] \\
\hline CPD1-3a-amino-5a androstane & Small molecule non-ATP competitive & CDK5/p35 & Skin cancer & [113] \\
\hline
\end{tabular}

an ATP-competitive inhibitor used to inhibit CDK5 activity [105, 117], it displays 10-fold higher therapeutic index than flavopiridol $[105,118-120]$ with a range of potency and pharmacokinetic parameters. In addition, small molecules like PHA-767491 and PHA793887 were reported to inhibit the activity of CDK5 by occupying the ATP binding sites of CDK5, exerting an anticancer effect on cervical cancer and breast cancer [101-104]. The ATP binding pocket on CDK5 is structurally conserved, and thus many ATP competitive inhibitors of CDK5 can nonspecifically bind with other CDKs [121].

Another class of CDK5 inhibitors can inhibit the CDK5 activity by abolishing the interaction of CDK5/ p35 complex. Roscovetine (Seliciclib, CYC202) was reported to inhibit the activity of CDK5 by competing for the binding site of p35 [106]. Tamoxifen can compete for binding with p35 and p25 to inhibit the CDK5 activity in breast cancer [69]. Besides, CDK5 inhibitory peptide (CIP), a polypeptide containing 125 amino acid residues derived from the peptide sequence 154-279aa of CDK5 activating protein $\mathrm{p} 35$, has a specific inhibitory activity on CDK5. CIP can bind to CDK5/p25 to form a ternary complex, blocking the interaction between CDK5 and p25 protein and thus inhibiting the activity of CDK5. A study showed that CIP can inhibit the abnormal phosphorylation of Tau induced by CDK $5 / \mathrm{p} 25$ [111]. Medicinal polypeptides and the FDA drugs, such as tamoxifen, exhibit both low side-effects and significant anticancer effects; however, their stability and bioavailability remain the shortcoming for clinical application, and maybe natural product source inhibitors are more compatible to achieve higher therapeutic effect [122, 123]. Lastly, as mentioned above, the activity of CDK5 is mainly controlled by various PTMs. For example, Ser159 phosphorylation and Lys33 acetylation negatively regulate the CDK5 activity, while Tyr15 phosphorylation links to CDK5 hyper-activation. It seems that targeting these PTM modifiers directly or indirectly could be a promising strategy for the inhibition of CDK5 activity and thus for the chemoprevention of cancer.

\section{Conclusion and outlook}

CDK5 is considered to be an atypical member of the CDKs, and its abnormal expression is involved in a variety of diseases, such as neurodegenerative diseases and cancer. During cancer progression, CDK5 serves as an oncogene to promote cell proliferation, migration and invasion. Currently, emerging types of PTM on CDK5 were identified, and were found to be involved in a wide range of cellular processes in cancer. ATP competitive inhibitors and drugs by targeting CDK5-p35 complexes are currently the major inhibitory tools to reduce CDK5 activity, however, their low specificity/stability and high toxicity remain handicap for clinical application. Increasing clinical studies have found that the CDK5 activity inhibitors are not specific, since they inhibit the activity of other kinases as well (Table 4). In this regard, specifically targeting PTMs on CDK5 may be a promising strategy for cancer treatment. This is possible because novel and rare PTMs that may significantly regulate the activity of CDK5 will be identified by employing the advancing technology of mass spectrometry and other analytical methods. The data reviewed above provide robust evidences to propose the inclusion of CDK5 and its PTMs in the group of novel molecules to be tested in preclinical research aiming at tumor intervention. The association of CDK5 inhibitors with the large number of available drugs currently under investigation is likely to offer additional rational therapeutic approaches for cancer. 


\section{Abbreviations}

ABD: Activators binding domain; ACC: Adrenocortical carcinoma; AD: Alzheimer's disease; AML: Acute myeloid leukemia; AEP1: Apurinic/ apyrimidine endonuclease 1; AR: Androgen receptor; ATM: Ataxiatelangiectasia mutant; ATP-BD: ATP binding domain; BICB: Breast invasive carcinoma breast; BIN1: Bridging integrator 1; CCCs: Cholangiocarcinoma; CDK5: Cyclin-dependent kinase 5; CDKs: Cyclin-dependent kinases; CHK1: Checkpoint kinase 1; CIP: CDK5 inhibitory peptide; CPD1: Cercosporin photosensitizer detoxification; ccRCC: Clear cell renal cell carcinoma; CRMP2: Collapsin Response Mediator Protein 2; DDR: DNA damage response; DLBC: Lymphoid neoplasm diffused large b-cell lymphoma; Drp1: Dynaminrelated protein 1; EGF: Epidermal growth factor; EGR1: Early growth response-1; Eme1: Essential Meiotic Structure-Specific Endonuclease 1; ER: Endoplasmic reticulum; ETS-1: Erythroblastosis virus transcription factor-1; EZH2: Enhancer of Zeste homolog 2; FAK: Focal adhesion kinase; FBW7: Fbox and WD repeat domain-containing 7; GBM: Glioblastoma; GCN5: General control of amino acid synthesis protein 5; Girdin: Ga-interacting vesicle

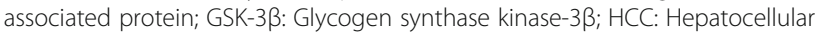
carcinoma; HIF1a: Hypoxia inducible factor 1a; IRF2: Interferon regulatory factor 2; IRF2BP2: Inhibit regulatory factor 2 binding protein 2; LGG: Lower grade glioma; Lung adeno: Lung adenocarcinoma; Lung squ: Lung squamous cell carcinoma; MAM: Mitochondria-associated endoplasmic reticulum membrane; MB: Medulloblastoma; MEN1: Menin; MPTP: Mitochondrial permeability transition pore; N-Myc: Neuroblastoma MYC Oncogene; NOS1: Nitric oxide synthase 1; Noxa: Nitric oxide synthase; PMAIP1: Phorbol-12-myristate-13-acetate-induced protein 1; NSCLC: Nonsmall cell lung cancer; p35: Cyclin dependent kinase 5 regulatory subunit 1, CDK5R1; p39: Cyclin dependent kinase 5 regulatory subunit 2, CDK5R2; PCPG: Pheochromocytoma and paraganglioma; PDAC: Pancreatic ductal adenocarcinoma; PD-L1: Programmed cell death ligand-1; PDPN: Podoplanin; PIN1: Peptidylprolyl cis/Trans isomerase NIMA-Interacting 1; PRC2: Polycomb repressive complex 2; pRCC: Papillary renal cell carcinoma; PRDX2: Peroxiredoxin-2; PTMs: Posttranslational modifications; Ral: Ras-Like; Rb: Retinoblastoma protein Reactive oxygen species; STMN1: Stathmin, microtubule decomposing protein; SIRT1: Sirtuin-1; Tau: Microtubule-associated protein Tau; TPX2: Target protein for Xklp2; TRIM59: Tripartite motif-containing 59; Uterine CS: Uterine carcinosarcoma; UM: Uveal melanoma

\section{Acknowledgements}

This work was supported by the National Key R\&D Program of China (2017YFA0505100), Guangdong Natural Science Research Grant (2019A1515010196), the National Natural Science Foundation of China (31770888), the Fundamental Research Funds for the Central Universities (11619303), and Guangdong "Climbing Program" Special Funds (pdjh2020a0064). We also thank Dr. Jing Zhang for revising the manuscript.

\section{Code availability}

Not applicable.

\section{Authors' contributions}

GBG and YW conceived the structure of manuscript. GBG, YS, YW and RDF drafted initial manuscript. YW and QYH revised the manuscript. All authors read and approved the final manuscript.

\section{Funding}

This work was supported by the National Key R\&D Program of China (2017YFA0505100), Guangdong Natural Science Research Grant (2019A1515010196), the National Natural Science Foundation of China (31770888), the Fundamental Research Funds for the Central Universities (11619303), and Guangdong "Climbing Program" Special Funds (pdjh2020a0064).

\section{Availability of data and materials}

All the data obtained and/or analyzed during the current study were available from the corresponding authors on reasonable request.

\section{Ethics approval and consent to participate} Not applicable.

\section{Consent for publication}

All authors give consent for the publication of manuscript in Molecular Biomedicine.

\section{Competing interests}

The authors declare no conflict of interest.

\section{Author details}

${ }^{1}$ MOE Key Laboratory of Tumor Molecular Biology and Key Laboratory of Functional Protein Research of Guangdong Higher Education Institutes, Institute of Life and Health Engineering, College of Life Science and Technology, Jinan University, Guangzhou 510632, China. ${ }^{2}$ Institute of Chinese Medical Sciences and State Key Laboratory of Quality Research in Chinese Medicine, University of Macau, Avenida da Universidade, Taipa, Macao SAR, China.

Received: 31 August 2020 Accepted: 9 February 2021

Published online: 20 July 2021

\section{References}

1. Arif A. Extraneuronal activities and regulatory mechanisms of the atypical cyclin-dependent kinase Cdk5. Biochem Pharmacol. 2012;84(8):985-93. https://doi.org/10.1016/j.bcp.2012.06.027.

2. Chohan TA, Qian H, Pan Y, Chen J-Z. Cyclin-dependent kinase-2 as a target for cancer therapy: progress in the development of CDK2 inhibitors as anticancer agents. Curr Med Chem. 2015;22(2):237-63. https://doi.org/10.2174/ 0929867321666141106113633.

3. Wilkaniec A, Czapski GA, Adamczyk A. Cdk5 at crossroads of protein oligomerization in neurodegenerative diseases: facts and hypotheses. J Neurochem. 2016;136(2):222-33. https://doi.org/10.1111/jnc.13365.

4. Zhong Y, Yang J, Xu WW, Wang Y, Zheng CC, Li B, et al. KCTD12 promotes tumorigenesis by facilitating CDC25B/CDK1/Aurora A-dependent G2/M transition. Oncogene. 2017;36(44):6177-89. https://doi.org/10.1038/onc.201 7.287.

5. Lenjisa JL, Tadesse S, Khair NZ, Kumarasiri M, Yu M, Albrecht H, et al. CDK5 in oncology: recent advances and future prospects. Future Med Chem. 2017;9(16):1939-62. https://doi.org/10.4155/fmc-2017-0097.

6. Lew J, Beaudette K, Litwin CM, Wang JH. Purification and characterization of a novel proline-directed protein kinase from bovine brain. J Biol Chem. 1992;267(19):13383-90. https://doi.org/10.1016/S0021-9258(18)42222-3.

7. Su SC, Tsai LH. Cyclin-dependent kinases in brain development and disease. Annu Rev Cell Dev Biol. 2011;27:465-91. https://doi.org/10.1146/annurevcellbio-092910-154023.

8. Zhang B, Tan VB, Lim KM, Tay TE. The activation and inhibition of cyclindependent kinase-5 by phosphorylation. Biochemistry. 2007:46(38):1084151. https://doi.org/10.1021/bi700890t.

9. Tarricone C, Dhavan R, Peng J, Areces LB, Tsai LH, Musacchio A. Structure and regulation of the CDK5-p25(nck5a) complex. Mol Cell. 2001;8(3):657-69. https://doi.org/10.1016/s1097-2765(01)00343-4.

10. Takasugi T, Minegishi S, Asada A, Saito T, Kawahara H, Hisanaga S. Two degradation pathways of the p35 Cdk5 (Cyclin-dependent kinase) activation subunit, dependent and independent of Ubiquitination. J Biol Chem. 2016; 291(9):4649-57. https://doi.org/10.1074/jbc.M115.692871.

11. Shupp A, Casimiro MC, Pestell RG. Biological functions of CDK5 and potential CDK5 targeted clinical treatments. Oncotarget. 2017;8(10):1737382. https://doi.org/10.18632/oncotarget.14538.

12. Sharma S, Zhang T, Michowski W, Rebecca WW, Xiao M, Ferretti R, et al. Targeting the cyclin-dependent kinase 5 in metastatic melanoma. Proc Natl Acad Sci U S A. 2020. https://doi.org/10.1073/pnas.1912617117.

13. Dhavan R, Tsai LH. A decade of CDK5. Nat Rev Mol Cell Biol. 2001;2(10):74959. https://doi.org/10.1038/35096019.

14. Kerokoski P, Suuronen T, Salminen A, Soininen H, Pirttilä T. Influence of phosphorylation of p35, an activator of cyclin-dependent kinase 5 (cdk5), on the proteolysis of p35. Brain Res Mol Brain Res. 2002;106(1-2):50-6. https:// doi.org/10.1016/s0169-328x(02)00409-6.

15. Minegishi S, Asada A, Miyauchi S, Fuchigami T, Saito T, Hisanaga S. Membrane association facilitates degradation and cleavage of the cyclindependent kinase 5 activators p35 and p39. Biochemistry. 2010;49(26):548293. https://doi.org/10.1021/bi100631f. 
16. Zhang L, Liu W, Szumlinski KK, Lew J. p10, the N-terminal domain of p35, protects against CDK5/p25-induced neurotoxicity. Proc Natl Acad Sci U S A. 2012;109(49):20041-6. https://doi.org/10.1073/pnas.1212914109.

17. Chew J, Chen MJ, Lee AY, Peng ZF, Chong KW, He L, et al. Identification of p10 as a neurotoxic product generated from the proteolytic cleavage of the neuronal Cdk5 activator. J Cell Biochem. 2010;111(5):1359-66. https://doi. org/10.1002/jcb.22864

18. Bei $Y$, Cheng $N$, Chen T, Shu Y, Yang Y, Yang N, et al. CDK5 Inhibition Abrogates TNBC Stem-Cell Property and Enhances Anti-PD-1 Therapy. Adv Sci (Weinheim, Baden-Wurttemberg, Germany). 2020;7(22):2001417. https:// doi.org/10.1002/advs.202001417.

19. Yushan R, Wenjie C, Suning H, Yiwu D, Tengfei Z, Madushi WM, et al. Insights into the clinical value of cyclin-dependent kinase 5 in glioma: a retrospective study. World J Surg Oncol. 2015;13:223. https://doi.org/10.11 86/s12957-015-0629-z.

20. Tabouret E, Wang H, Amin N, Jung J, Appay R, Cui J, et al. TP5, a Peptide Inhibitor of Aberrant and Hyperactive CDK5/p25: A Novel Therapeutic Approach against Glioblastoma. Cancers (Basel). 2020;12(7). https://doi.org/1 0.3390/cancers12071935.

21. Lu JW, Chang JG, Yeh KT, Chen RM, Tsai JJ, Hu RM. Decreased expression of p39 is associated with a poor prognosis in human hepatocellular carcinoma. Med Oncol. 2011;28(Suppl 1):S239-45. https://doi.org/10.1007/ s12032-010-9707-9.

22. Li W, Allen ME, Rui Y, Ku L, Liu G, Bankston AN, et al. p39 is responsible for increasing Cdk5 activity during postnatal neuron differentiation and governs neuronal network formation and epileptic responses. J Neurosci. 2016; 36(44):11283-94. https://doi.org/10.1523/jneurosci.1155-16.2016.

23. Zhuang $K$, Zhang J, Xiong M, Wang $X$, Luo $X$, Han L, et al. CDK5 functions as a tumor promoter in human colorectal cancer via modulating the ERK5-AP1 axis. Cell Death Dis. 2016;7(10):e2415. https://doi.org/10.1038/cddis.201 6.333.

24. Liang Q, Li L, Zhang J, Lei Y, Wang L, Liu D-X, et al. CDK5 is essential for TGF- $\beta 1$-induced epithelial-mesenchymal transition and breast cancer progression. Sci Rep. 2013;3:2932. https://doi.org/10.1038/srep02932.

25. Zeng J, Xie S, Liu Y, Shen C, Song X, Zhou G-L, et al. CDK5 functions as a tumor promoter in human lung cancer. J Cancer. 2018;9(21):3950-61. https://doi.org/10.7150/jca.25967.

26. Pozo K, Castro-Rivera E, Tan C, Plattner F, Schwach G, Siegl V, et al. The role of Cdk5 in neuroendocrine thyroid cancer. Cancer Cell. 2013;24(4):499-511. https://doi.org/10.1016/j.ccr.2013.08.027.

27. Xie W, Wang H, He Y, Li D, Gong L, Zhang Y. CDK5 and its activator P35 in normal pituitary and in pituitary adenomas: relationship to VEGF expression. Int J Biol Sci. 2014;10(2):192-9. https://doi.org/10.7150/ijbs.7770.

28. Oner M, Lin E, Chen M-C, Hsu F-N, Shazzad Hossain Prince GM, Chiu K-Y, et al. Future aspects of CDK5 in prostate cancer: from pathogenesis to therapeutic implications. Int J Mol Sci. 2019;20(16). https://doi.org/10.3390/ ijms20163881.

29. Liu B, Li L, Yang G, Geng C, Luo Y, Wu W, et al. PARP inhibition suppresses GR-MYCN-CDK5-RB1-E2F1 signaling and neuroendocrine differentiation in castration-resistant prostate cancer. Clin Cancer Res. 2019;25(22):6839-51. https://doi.org/10.1158/1078-0432.ccr-19-0317.

30. Zhuang K, Huang C, Leng L, Zheng H, Gao Y, Chen G, et al. Neuron-specific Menin deletion leads to synaptic dysfunction and cognitive impairment by modulating p35 expression. Cell Rep. 2018;24(3):701-12. https://doi.org/10.1 016/j.celrep.2018.06.055.

31. Chen F, Wang Q, Wang X, Studzinski GP. Up-regulation of Egr1 by 1,25dihydroxyvitamin D3 contributes to increased expression of p35 activator of cyclin-dependent kinase 5 and consequent onset of the terminal phase of HL60 cell differentiation. Cancer Res. 2004;64(15):5425-33. https://doi.org/1 0.1158/0008-5472.can-04-0806.

32. Kapora E, Feng S, Liu W, Sakhautdinova I, Gao B, Tan W. MicroRNA-505-5p functions as a tumor suppressor by targeting cyclin-dependent kinase 5 in cervical cancer. Biosci Rep. 2019;39(7). https://doi.org/10.1042/bsr20191221.

33. Asada A, Yamamoto N, Gohda M, Saito T, Hayashi N, Hisanaga S. Myristoylation of p39 and p35 is a determinant of cytoplasmic or nuclear localization of active cyclin-dependent kinase 5 complexes. J Neurochem. 2008;106(3):1325-36. https://doi.org/10.1111/j.1471-4159.2008.05500.x.

34. Asada A, Saito T, Hisanaga S. Phosphorylation of p35 and p39 by Cdk5 determines the subcellular location of the holokinase in a phosphorylationsite-specific manner. J Cell Sci. 2012;125(Pt 14):3421-9. https://doi.org/1 $0.1242 /$ jcs. 100503
35. Zhu YS, Saito T, Asada A, Maekawa S, Hisanaga S. Activation of latent cyclindependent kinase 5 (Cdk5)-p35 complexes by membrane dissociation. J Neurochem. 2005;94(6):1535-45. https://doi.org/10.1111/j.1471-4159.2005. 03301.x.

36. Liang S, Wei FY, Wu YM, Tanabe K, Abe T, Oda Y, et al. Major Cdk5dependent phosphorylation sites of amphiphysin 1 are implicated in the regulation of the membrane binding and endocytosis. J Neurochem. 2007; 102(5):1466-76. https://doi.org/10.1111/j.1471-4159.2007.04507.x.

37. NavaneethaKrishnan S, Rosales JL, Lee KY. mPTP opening caused by Cdk5 loss is due to increased mitochondrial $\mathrm{Ca}(2+)$ uptake. Oncogene. 2020; 39(13):2797-806. https://doi.org/10.1038/s41388-020-1188-5.

38. Malumbres M, Barbacid M. Cell cycle, CDKs and cancer: a changing paradigm. Nat Rev Cancer. 2009;9(3):153-66. https://doi.org/10.1038/nrc2 602.

39. Li C, Zhang G, Zhao L, Ma Z, Chen H. Metabolic reprogramming in cancer cells: glycolysis, glutaminolysis, and $\mathrm{BCl}-2$ proteins as novel therapeutic targets for cancer. World J Surg Oncol. 2016;14(1):15. https://doi.org/10.11 86/s12957-016-0769-9.

40. Huang $\mathrm{P}-\mathrm{H}$, Chen M-C, Peng $\mathrm{Y}-\mathrm{T}$, Kao W-H, Chang $\mathrm{C}-\mathrm{H}$, Wang $\mathrm{Y}-\mathrm{C}$, et al. Cdk5 directly targets nuclear P21CIP1 and promotes cancer cell growth. Cancer Res. 2016;76(23):6888-900. https://doi.org/10.1158/0008-5472.CAN-1 5-3253.

41. Liu JL, Wang XY, Huang BX, Zhu F, Zhang RG, Wu G. Expression of CDK5/ p35 in resected patients with non-small cell lung cancer: relation to prognosis. Med Oncol. 2011;28(3):673-8. https://doi.org/10.1007/s12032-0109510-7.

42. Eggers JP, Grandgenett PM, Collisson EC, Lewallen ME, Tremayne J, Singh PK, et al. Cyclin-dependent kinase 5 is amplified and overexpressed in pancreatic cancer and activated by mutant K-Ras. Clin Cancer Res. 2011; 17(19):6140-50. https://doi.org/10.1158/1078-0432.CCR-10-2288.

43. Lin $\mathrm{H}$, Chen $\mathrm{M}-\mathrm{C}$, Chiu C-Y, Song $\mathrm{Y}-\mathrm{M}$, Lin S-Y. Cdk5 regulates STAT3 activation and cell proliferation in medullary thyroid carcinoma cells. J Biol Chem. 2007;282(5):2776-84. https://doi.org/10.1074/jbc.M6072342 00.

44. Wei K, Ye Z, Li Z, Dang Y, Chen X, Huang N, et al. An immunohistochemical study of cyclin-dependent kinase 5 (CDK5) expression in non-small cell lung cancer (NSCLC) and small cell lung cancer (SCLC): a possible prognostic biomarker. World J Surg Oncol. 2016;14(1):34. https://doi.org/10.1186/s12 957-016-0787-7.

45. Liu R, Tian B, Gearing M, Hunter S, Ye K, Mao Z. Cdk5-mediated regulation of the PIKE-A-Akt pathway and glioblastoma cell invasion. Proc Natl Acad Sci U S A. 2008;105(21):7570-5. https://doi.org/10.1073/pnas.0712306105.

46. Moutal A, Villa LS, Yeon SK, Householder KT, Park KD, Sirianni RW, et al. CRMP2 phosphorylation drives glioblastoma cell proliferation. Mol Neurobiol. 2018:55(5):4403-16. https://doi.org/10.1007/s12035-017-0653-9.

47. Futatsugi A, Utreras E, Rudrabhatla P, Jaffe H, Pant HC, Kulkarni AB. Cyclindependent kinase 5 regulates $\mathrm{E} 2 \mathrm{~F}$ transcription factor through phosphorylation of Rb protein in neurons. Cell Cycle. 2012;11(8):1603-10. https://doi.org/10.4161/cc.20009.

48. Zhang X, Wang J, Jia Y, Liu T, Wang M, Lv W, et al. CDK5 neutralizes the tumor suppressing effect of BIN1 via mediating phosphorylation of c-MYC at Ser-62 site in NSCLC. Cancer Cell Int. 2019;19:226. https://doi.org/10.1186/ s12935-019-0952-5.

49. Sang Y, Li Y, Zhang Y, Alvarez AA, Yu B, Zhang W, et al. CDK5-dependent phosphorylation and nuclear translocation of TRIM59 promotes macroH2A1 ubiquitination and tumorigenicity. Nat Commun. 2019;10(1):4013. https:// doi.org/10.1038/s41467-019-12001-2.

50. Jeggo PA, Pearl LH, Carr AM. DNA repair, genome stability and cancer: a historical perspective. Nat Rev Cancer. 2016;16(1):35-42. https://doi.org/10.1 038/nrc.2015.4.

51. Haber JE. Deciphering the DNA damage response. Cell. 2015;162(6):1183-5. https://doi.org/10.1016/j.cell.2015.08.034.

52. O'Connor MJ. Targeting the DNA damage response in cancer. Mol Cell. 2015;60(4):547-60. https://doi.org/10.1016/j.molcel.2015.10.040.

53. Tian B, Yang Q, Mao Z. Phosphorylation of ATM by Cdk5 mediates DNA damage signalling and regulates neuronal death. Nat Cell Biol. 2009;11(2): 211-8. https://doi.org/10.1038/ncb1829.

54. Huang $E_{1}$ Qu D, Zhang $Y$, Venderova $K$, Haque ME, Rousseaux MWC, et al. The role of Cdk5-mediated apurinic/apyrimidinic endonuclease 1 phosphorylation in neuronal death. Nat Cell Biol. 2010;12(6):563-71. https:// doi.org/10.1038/ncb2058. 
55. Courapied S, Sellier H, de Carné Trécesson S, Vigneron A, Bernard AC, Gamelin E, et al. The cdk5 kinase regulates the STAT3 transcription factor to prevent DNA damage upon topoisomerase I inhibition. J Biol Chem. 2010; 285(35):26765-78. https://doi.org/10.1074/jbc.M109.092304.

56. Ehrlich SM, Liebl J, Ardelt MA, Lehr T, De Toni EN, Mayr D, et al. Targeting cyclin dependent kinase 5 in hepatocellular carcinoma--a novel therapeutic approach. J Hepatol. 2015;63(1):102-13. https://doi.org/10.1016/j.jhep.2015. 01.031.

57. Yu H-P, Xie J-M, Li B, Sun Y-H, Gao Q-G, Ding Z-H, et al. TIGAR regulates DNA damage and repair through pentosephosphate pathway and Cdk5ATM pathway. Sci Rep. 2015;5:9853. https://doi.org/10.1038/srep09853.

58. Hsu F-N, Chen M-C, Chiang M-C, Lin E, Lee Y-T, Huang P-H, et al. Regulation of androgen receptor and prostate cancer growth by cyclin-dependent kinase 5. J Biol Chem. 2011;286(38):33141-9. https://doi.org/10.1074/jbc. M111.252080.

59. Kour S, Rana S, Contreras Jl, King HM, Robb CM, Sonawane YA, et al. CDK5 inhibitor downregulates $\mathrm{MCl}-1$ and sensitizes pancreatic cancer cell lines to Navitoclax. Mol Pharmacol. 2019;96(4):419-29. https://doi.org/10.1124/ mol.119.116855.

60. Pozo K, Bibb JA. The emerging role of Cdk5 in cancer. Trends Cancer. 2016; 2(10):606-18. https://doi.org/10.1016/j.trecan.2016.09.001.

61. Bisht S, Nolting J, Schütte U, Haarmann J, Jain P, Shah D, et al. Cyclindependent kinase 5 (CDK5) controls melanoma cell motility, invasiveness, and metastatic spread-identification of a promising novel therapeutic target. Transl Oncol. 2015;8(4):295-307. https://doi.org/10.1016/j.tranon.2015.06.002.

62. Bhandari D, Lopez-Sanchez I, To A, Lo IC, Aznar N, Leyme A, et al. Cyclindependent kinase 5 activates guanine nucleotide exchange factor GIV/ Girdin to orchestrate migration-proliferation dichotomy. Proc Natl Acad Sci U S A. 2015;112(35):E4874-83. https://doi.org/10.1073/pnas.1514157112.

63. Rouzier R, Rajan R, Wagner P, Hess KR, Gold DL, Stec J, et al. Microtubuleassociated protein tau: a marker of paclitaxel sensitivity in breast cancer. Proc Natl Acad Sci U S A. 2005;102(23):8315-20. https://doi.org/10.1073/pna S.0408974102.

64. Grant NJ, Coates PJ, Woods YL, Bray SE, Morrice NA, Hastie CJ, et al. Phosphorylation of a splice variant of collapsin response mediator protein 2 in the nucleus of tumour cells links cyclin dependent kinase-5 to oncogenesis. BMC Cancer. 2015;15:885. https://doi.org/10.1186/s12885-015-1 $691-1$

65. Nie W, Xu M-d, Gan L, Huang H, Xiu Q, Li B. Overexpression of stathmin 1 is a poor prognostic biomarker in non-small cell lung cancer. Lab Invest. 2015; 95(1):56-64. https://doi.org/10.1038/labinvest.2014.124.

66. Huang C, Rajfur Z, Yousefi N, Chen Z, Jacobson K, Ginsberg MH. Talin phosphorylation by Cdk5 regulates Smurf1-mediated Talin head ubiquitylation and cell migration. Nat Cell Biol. 2009;11(5):624-30. https:// doi.org/10.1038/ncb1868

67. Jin X, Yang C, Fan P, Xiao J, Zhang W, Zhan S, et al. CDK5/FBW7-dependent ubiquitination and degradation of $\mathrm{EZH} 2$ inhibits pancreatic cancer cell migration and invasion. J Biol Chem. 2017;292(15):6269-80. https://doi.org/1 0.1074/jbc.M116.764407.

68. Krishnan H, Retzbach EP, Ramirez MI, Liu T, Li H, Miller WT, et al. PKA and CDK5 can phosphorylate specific serines on the intracellular domain of podoplanin (PDPN) to inhibit cell motility. Exp Cell Res. 2015;335(1):115-22. https://doi.org/10.1016/j.yexcr.2015.04.019.

69. Wang F, Zhao W, Gao Y, Zhou J, Li H, Zhang G, et al. CDK5-mediated phosphorylation and stabilization of TPX2 promotes hepatocellular tumorigenesis. J Exp Clin Cancer Res. 2019;38(1):286. https://doi.org/10.1186/ s13046-019-1297-6.

70. Herzog J, Ehrlich SM, Pfitzer L, Liebl J, Fröhlich T, Arnold GJ, et al. Cyclindependent kinase 5 stabilizes hypoxia-inducible factor-1a: a novel approach for inhibiting angiogenesis in hepatocellular carcinoma. Oncotarget. 2016; 7(19):27108-21. https://doi.org/10.18632/oncotarget.8342.

71. Merk H, Zhang S, Lehr T, Müller C, Ulrich M, Bibb JA, et al. Inhibition of endothelial Cdk5 reduces tumor growth by promoting non-productive angiogenesis. Oncotarget. 2016;7(5):6088-104. https://doi.org/10.18632/ oncotarget.6842

72. Dorand RD, Nthale J, Myers JT, Barkauskas DS, Avril S, Chirieleison SM, et al, Cdk5 disruption attenuates tumor PD-L1 expression and promotes antitumor immunity. Science. 2016;353(6297):399-403. https://doi.org/10.112 6/science.aae0477.

73. Teng ACT, Al-Montashiri NAM, Cheng BLM, Lou P, Ozmizrak P, Chen H-H, et al. Identification of a phosphorylation-dependent nuclear localization motif in interferon regulatory factor 2 binding protein 2. PLoS One. 2011; 6(8):e24100. https://doi.org/10.1371/journal.pone.0024100.

74. Deng H, Tan S, Gao X, Zou C, Xu C, Tu K, et al. Knocking out mediated by CRISPR-Cas9 genome editing for PD-L1 attenuation and enhanced antitumor immunity. Acta Pharm Sin B. 2020;10(2):358-73. https://doi.org/1 0.1016/j.apsb.2019.07.004.

75. Hsu J-M, Li C-W, Lai Y-J, Hung M-C. Posttranslational modifications of PD-L1 and their applications in cancer therapy. Cancer Res. 2018;78(22):6349-53. https://doi.org/10.1158/0008-5472.CAN-18-1892.

76. Macek B, Forchhammer K, Hardouin J, Weber-Ban E, Grangeasse C, Mijakovic I. Protein post-translational modifications in bacteria. Nat Rev Microbiol. 2019;17(11):651-64. https://doi.org/10.1038/s41579-019-0243-0.

77. Wang Y, Zhang J, Li B, He Q-Y. Advances of proteomics in novel PTM discovery: applications in cancer therapy. Small Methods. 2019;3(5):1900041. https://doi.org/10.1002/smtd.201900041.

78. Zukerberg LR, Patrick GN, Nikolic M, Humbert S, Wu CL, Lanier LM, et al. Cables links Cdk5 and c-Abl and facilitates Cdk5 tyrosine phosphorylation, kinase upregulation, and neurite outgrowth. Neuron. 2000;26(3):633-46. https://doi.org/10.1016/s0896-6273(00)81200-3.

79. Shah K, Lahiri DK. Cdk5 activity in the brain - multiple paths of regulation. J Cell Sci. 2014;127:2391-400. https://doi.org/10.1242/jcs.147553.

80. Takahashi S, Saito T, Hisanaga SI, Pant HC, Kulkarni AB. Tau phosphorylation by cyclin-dependent kinase 5/p39 during brain development reduces its affinity for microtubules. J Biol Chem. 2003;278(12):10506-15. https://doi. org/10.1074/jbc.M211964200.

81. Mishra D, Patel V, Banerjee D. Nitric Oxide and S-Nitrosylation in Cancers: Emphasis on Breast Cancer. Breast Cancer (Auckl). 2020;14: 1178223419882688. https://doi.org/10.1177/1178223419882688.

82. Raines KW, Cao G-L, Lee EK, Rosen GM, Shapiro P. Neuronal nitric oxide synthase-induced S-nitrosylation of $\mathrm{H}$-Ras inhibits calcium ionophoremediated extracellular-signal-regulated kinase activity. Biochem J. 2006; 397(2):329-36. https://doi.org/10.1042/BJ20052002.

83. Qu J, Nakamura T, Holland EA, McKercher SR, Lipton SA. S-nitrosylation of Cdk5: potential implications in amyloid- $\beta$-related neurotoxicity in Alzheimer disease. Prion. 2012;6(4):364-70. https://doi.org/10.4161/pri.21250.

84. Cho D-H, Nakamura T, Fang J, Cieplak P, Godzik A, Gu Z, et al. Snitrosylation of Drp1 mediates beta-amyloid-related mitochondrial fission and neuronal injury. Science (New York, NY). 2009:324(5923):102-5. https:// doi.org/10.1126/science.1171091.

85. Qu J, Nakamura T, Cao G, Holland EA, McKercher SR, Lipton SA. SNitrosylation activates Cdk5 and contributes to synaptic spine loss induced by beta-amyloid peptide. Proc Natl Acad Sci U S A. 2011;108(34):14330-5. https://doi.org/10.1073/pnas.1105172108.

86. Zhang P, Yu P-C, Tsang AHK, Chen Y, Fu AKY, Fu W-Y, et al. S-Nitrosylation of cyclin-dependent kinase 5 (Cdk5) regulates its kinase activity and dendrite growth during neuronal development. J Neurosci. 2010;30(43): 14366. https://doi.org/10.1523/JNEUROSCI.3899-10.2010.

87. Zhang P, Fu W-Y, Fu AKY, Ip NY. S-nitrosylation-dependent proteasomal degradation restrains C $\mathrm{dk} 5$ activity to regulate hippocampal synaptic strength. Nat Commun. 2015;6:8665. https://doi.org/10.1038/ncomms9665.

88. Bischof O, Dejean A. SUMO is growing senescent. Cell Cycle. 2007:6(6):67781. https://doi.org/10.4161/cc.6.6.4021

89. Meinecke I, Cinski A, Baier A, Peters MA, Dankbar B, Wille A, et al. Modification of nuclear PML protein by SUMO-1 regulates Fas-induced apoptosis in rheumatoid arthritis synovial fibroblasts. Proc Natl Acad Sci U S A. 2007;104(12):5073-8. https://doi.org/10.1073/pnas.0608773104.

90. Lee JS, Choi HJ, Baek SH. Sumoylation and its contribution to cancer. Adv Exp Med Biol. 2017;963:283-98. https://doi.org/10.1007/978-3-31950044-7 17.

91. Tsai LH, Delalle I, Caviness VS, Chae T, Harlow E. p35 is a neural-specific regulatory subunit of cyclin-dependent kinase 5. Nature. 1994;371(6496): 419-23. https://doi.org/10.1038/371419a0

92. Büchner A, Krumova P, Ganesan S, Bähr M, Eckermann K, Weishaupt JH. Sumoylation of p35 modulates p35/cyclin-dependent kinase (Cdk) 5 complex activity. Neuromolecular Med. 2015;17(1):12-23. https://doi.org/10.1 007/s12017-014-8336-4.

93. Lee J, Yun N, Kim C, Song M-Y, Park K-S, Oh YJ. Acetylation of cyclindependent kinase 5 is mediated by GCN5. Biochem Biophys Res Commun. 2014;447(1):121-7. https://doi.org/10.1016/j.bbrc.2014.03.118.

94. Lee J, Ko YU, Chung Y, Yun N, Kim M, Kim K, et al. The acetylation of cyclindependent kinase 5 at lysine 33 regulates kinase activity and neurite length 
in hippocampal neurons. Sci Rep. 2018;8(1):13676. https://doi.org/10.1038/ s41598-018-31785-9.

95. Choudhary C, Kumar C, Gnad F, Nielsen ML, Rehman M, Walther TC, et al. Lysine acetylation targets protein complexes and co-regulates major cellular functions. Science (New York, NY). 2009;325(5942):834-40. https://doi.org/1 $0.1126 /$ science.1175371.

96. Weinert BT, Wagner SA, Horn H, Henriksen P, Liu WR, Olsen JV, et al. Proteome-wide mapping of the Drosophila acetylome demonstrates a high degree of conservation of lysine acetylation. Scil Signal. 2011;4(183):ra48. https://doi.org/10.1126/scisignal.2001902.

97. Bai B, Liang Y, Xu C, Lee MY, Xu A, Wu D, et al. Cyclin-dependent kinase 5mediated hyperphosphorylation of sirtuin-1 contributes to the development of endothelial senescence and atherosclerosis. Circulation. 2012;126(6):72940. https://doi.org/10.1161/CIRCULATIONAHA.112.118778.

98. Rizzolio F, Tuccinardi T, Caligiuri I, Lucchetti C, Giordano A. CDK inhibitors: from the bench to clinical trials. Curr Drug Targets. 2010;11(3):279-90. https://doi.org/10.2174/138945010790711978.

99. Cicenas J, Valius M. The CDK inhibitors in cancer research and therapy. J Cancer Res Clin Oncol. 2011;137(10):1409-18. https://doi.org/10.1007/ s00432-011-1039-4

100. Goel S, DeCristo MJ, McAllister SS, Zhao JJ. CDK4/6 inhibition in cancer: beyond cell cycle arrest. Trends Cell Biol. 2018;28(11):911-25. https://doi. org/10.1016/j.tcb.2018.07.002.

101. Moiseeva TN, Qian C, Sugitani N, Osmanbeyoglu HU, Bakkenist CJ. WEE1 kinase inhibitor AZD1775 induces CDK1 kinase-dependent origin firing in unperturbed G1- and S-phase cells. Proc Natl Acad Sci U S A. 2019;116(48): 23891-3. https://doi.org/10.1073/pnas.1915108116.

102. McLaughlin RP, He J, van der Noord VE, Redel J, Foekens JA, Martens JWM, et al. A kinase inhibitor screen identifies a dual cdc7/CDK9 inhibitor to sensitise triple-negative breast cancer to EGFR-targeted therapy. Breast Cancer Res. 2019;21 (1):77. https://doi.org/10.1186/s13058-019-1161-9.

103. Nguyen TK, Grant S. Dinaciclib (SCH727965) inhibits the unfolded protein response through a CDK1- and 5-dependent mechanism. Mol Cancer Ther. 2014;13(3):662-74. https://doi.org/10.1158/1535-7163.MCT-13-0714.

104. Inoue-Yamauchi A, Jeng PS, Kim K, Chen H-C, Han S, Ganesan YT, et al. Targeting the differential addiction to anti-apoptotic BCL-2 family for cancer therapy. Nat Commun. 2017;8:16078. https://doi.org/10.1038/ncomms16078.

105. Parry D, Guzi T, Shanahan F, Davis N, Prabhavalkar D, Wiswell D, et al. Dinaciclib (SCH 727965), a novel and potent cyclin-dependent kinase inhibitor. Mol Cancer Ther. 2010;9(8):2344. https://doi.org/10.1158/1535-71 63.MCT-10-0324.

106. Whittaker SR, Walton MI, Garrett MD, Workman P. The Cyclin-dependent kinase inhibitor CYC202 (R-roscovitine) inhibits retinoblastoma protein phosphorylation, causes loss of Cyclin D1, and activates the mitogenactivated protein kinase pathway. Cancer Res. 2004;64(1):262-72. https://doi. org/10.1158/0008-5472.can-03-0110.

107. Meijer L, Thunnissen AM, White AW, Garnier M, Nikolic M, Tsai LH, et al. Inhibition of cyclin-dependent kinases, GSK-3beta and CK1 by hymenialdisine, a marine sponge constituent. Chem Biol. 2000;7(1):51-63. https://doi.org/10.1016/s1074-5521(00)00063-6.

108. Villerbu N, Gaben A-M, Redeuilh G, Mester J. Cellular effects of purvalanol a: a specific inhibitor of cyclin-dependent kinase activities. Int J Cancer. 2002; 97(6):761-9. https://doi.org/10.1002/ijc.10125.

109. Yan L, Lai F, Chen X, Xiao Z. Discovery of novel indirubin-3'-monoxime derivatives as potent inhibitors against CDK2 and CDK9. Bioorg Med Chem Lett. 2015;25(11):2447-51. https://doi.org/10.1016/j.bmcl.2015.03.066.

110. Squires MS, Feltell RE, Wallis NG, Lewis EJ, Smith D-M, Cross DM, et al. Biological characterization of AT7519, a small-molecule inhibitor of cyclindependent kinases, in human tumor cell lines. Mol Cancer Ther. 2009;8(2): 324-32. https://doi.org/10.1158/1535-7163.MCT-08-0890.

111. Zheng YL, Li C, Hu YF, Cao L, Wang H, Li B, et al. Cdk5 inhibitory peptide (CIP) inhibits Cdk5/p25 activity induced by high glucose in pancreatic beta cells and recovers insulin secretion from p25 damage. PLoS One. 2013;8(9): e63332. https://doi.org/10.1371/journal.pone.0063332.

112. Shukla V, Zheng Y-L, Mishra SK, Amin ND, Steiner J, Grant P, et al. A truncated peptide from $\mathrm{p} 35, \mathrm{a} \mathrm{Cdk} 5$ activator, prevents Alzheimer's disease phenotypes in model mice. FASEB J. 2013;27(1):174-86. https://doi.org/10.1 096/fj.12-217497.

113. Liu H, Liu K, Huang Z, Park C-M, Thimmegowda NR, Jang J-H, et al. A chrysin derivative suppresses skin cancer growth by inhibiting cyclin- dependent kinases. J Biol Chem. 2013;288(36):25924-37. https://doi.org/10.1 074/jbc.M113.464669.

114. Mapelli M, Massimiliano L, Crovace C, Seeliger MA, Tsai L-H, Meijer L, et al. Mechanism of CDK5/p25 binding by CDK inhibitors. J Med Chem. 2005; 48(3):671-9. https://doi.org/10.1021/jm049323m.

115. Zhang B, Corbel C, Guéritte F, Couturier C, Bach S, Tan VBC. An in silico approach for the discovery of CDK5/p25 interaction inhibitors. Biotechnol J. 2011;6(7):871-81. https://doi.org/10.1002/biot.201100139.

116. Peyressatre M, Prével C, Pellerano M, Morris MC. Targeting cyclin-dependent kinases in human cancers: from small molecules to peptide inhibitors. Cancers (Basel). 2015;7(1):179-237. https://doi.org/10.3390/cancers7010179.

117. Paruch K, Dwyer MP, Alvarez C, Brown C, Chan T-Y, Doll RJ, et al. Discovery of Dinaciclib (SCH 727965): a potent and selective inhibitor of cyclindependent kinases. ACS Med Chem Lett. 2010;1(5):204-8. https://doi.org/1 $0.1021 / \mathrm{ml} 100051 \mathrm{~d}$.

118. Rasool RU, Natesan R, Deng Q, Aras S, Lal P, Sander Effron S, et al. CDK7 inhibition suppresses castration-resistant prostate cancer through MED1 inactivation. Cancer Discov. 2019;9(11):1538-55. https://doi.org/10.1158/21 59-8290.CD-19-0189.

119. Qiu Z, Li H, Zhang Z, Zhu ZF, He S, Wang XJ, et al. A pharmacogenomic landscape in human liver cancers. Cancer Cell. 2019;36(2):179-93.e11. https://doi.org/10.1016/j.ccell.2019.07.001.

120. Hashiguchi T, Bruss N, Best S, Lam V, Danilova O, Paiva CJ, et al. Cyclindependent Kinase-9 is a therapeutic target in MYC-expressing diffuse large B-cell lymphoma. Mol Cancer Ther. 2019;18(9):1520-32. https://doi.org/10.11 58/1535-7163.mct-18-1023.

121. Asghar U, Witkiewicz AK, Turner NC, Knudsen ES. The history and future of targeting cyclin-dependent kinases in cancer therapy. Nat Rev Drug Discov. 2015;14(2):130-46. https://doi.org/10.1038/nrd4504.

122. Zhang J, Zhou Y, Li N, Liu WT, Liang JZ, Sun Y, et al. Curcumol overcomes TRAlL resistance of non-small cell lung cancer by targeting NRH: Quinone Oxidoreductase 2 (NQO2). Adv Sci. 2020;7(22):2002306. https://doi.org/10.1 002/advs.202002306.

123. Zhang J, Sun Y, Zhong L-Y, Yu N-N, Ouyang L, Fang R-D, et al. Structurebased discovery of neoandrographolide as a novel inhibitor of Rab5 to suppress cancer growth. Comput Struct Biotechnol J. 2020;18:3936-46. https://doi.org/10.1016/j.csbj.2020.11.033.

\section{Publisher's Note}

Springer Nature remains neutral with regard to jurisdictional claims in published maps and institutional affiliations. 